\title{
Un encuentro fructífero: Los aportes de Juan Carlos Garavaglia y Jorge Gelman a la historiografía argentina, 1987-2016
}

Raúl Fradkin y DANIEl SANTILli

PALABRAS CLAVE: historia agraria, Argentina, historiografía, siglo XIX.

JEL CODES: N01 N16 N36 N46.

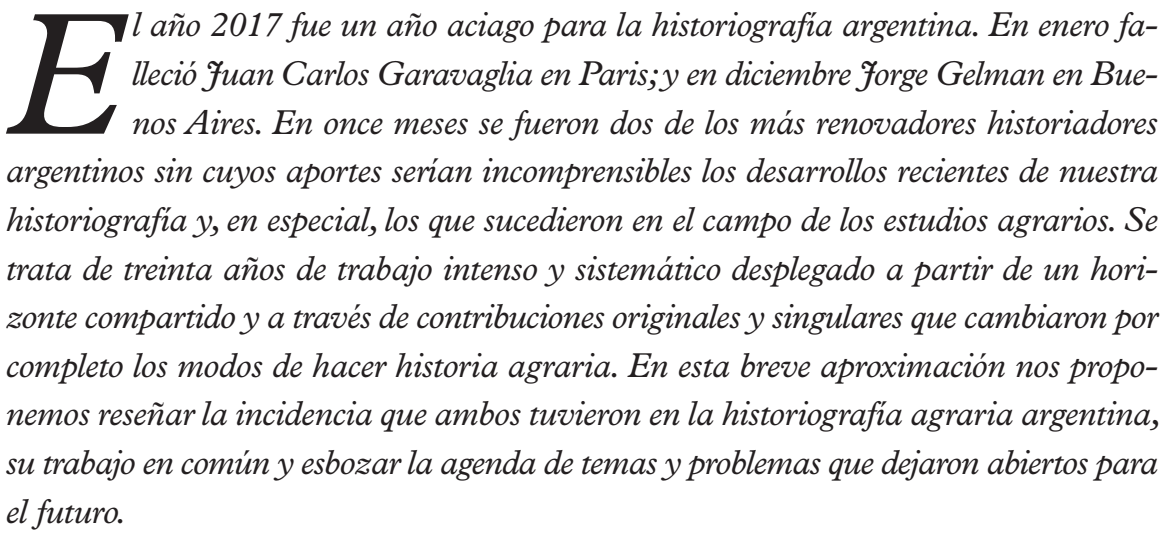




\title{
A fruitful encounter: The contributions of Juan Carlos Garavaglia and Jorge Gelman to the historiography of Argentina. 1987-2016
}

\author{
KEYWORDS: Agrarian History, Argentina, Historiography, 19 $^{\text {th }}$ cen- \\ tury.
}

JEL CODES: N01 N16 N36 N46.

he year 2017 was an unfortunate one for Argentine historiography. In Fan-
uary, fuan Carlos Garavaglia passed away in Paris, followed in December
by forge Gelman in Buenos Aires. Within eleven months, two of the most innovative Argentine historians faded into history. Recent developments in our historiography would be incomprehensible without their contributions, particularly in the field of agrarian studies. Their original and unique legacy, reflecting thirty years of intense work and a common research horizon, have completely changed how agrarian history is done in Argentina. In this brief essay, we attempt to outline the impact of both historians, the main lines of their work in common, and an agenda for the topics and issues they left open to future research.

Recibido: 2019-03-11 - Revisado: 2019-08-13 - Aceptado: 2019-08-14

Raúl Fradkin [orcid.org/0000-0002-0006-8668] es investigador de Instituto Ravignani (Universidad de Buenos Aires-CONICET) y profesor titular de Historia de América en el Departamento de Historia de la Facultad de Filosofía y Letras de la Universidad de Buenos Aires y en el Departamento de Ciencias Sociales de la Universidad Nacional de Luján. Dirección para correspondencia: 25 de mayo, 221, piso 2, 1002 Buenos Aires (Argentina).C.e.: raul.fradkin@gmail.com

Daniel Santilli [orcid.org/0000-0001-7236-3095] es investigador en el Instituto Ravignani (Universidad de Buenos Aires-CONICET) y docente de cátedra de Historia Argentina I de la carrera de Historia de la Facultad de Filosofía y Letras de la Universidad de Buenos Aires. Dirección para correspondencia: 25 de mayo, 221, piso 2, 1002 Buenos Aires (Argentina).C.e.:dvsantilli@gmail.com 
El año 2017 fue un año aciago para la historiografía argentina. En enero falleció Juan Carlos Garavaglia en París; y en diciembre Jorge Gelman en Buenos Aires. En once meses se fueron dos de los más influyentes protagonistas de la renovación historiográfica argentina. Más allá de la enorme pérdida personal que significa para quienes fuimos sus amigos y compañeros, el vacío que dejan en nuestro quehacer es inmenso. Por eso, más que lamentarnos queremos recordarlos centrándonos en una dimensión central de sus trayectorias: su trabajo en común, su convergencia y colaboración para darle impulso y direcciones inéditas e innovadoras a nuestra y otras historiografías. Recuperar la riqueza y fertilidad de esa interacción, que propició un amplio abanico de trabajos, entusiasmos y vocaciones, es nuestro modo de afrontar ese enorme vacío y rendirles humilde pero justificado homenaje.

Aunque ambos estuvieron exiliados en Francia y se formaron bajo la dirección de Ruggiero Romano, recién se conocieron en Buenos Aires a mediados de los ochenta, cuando la primavera política de 1984 permitió que pudieran retornar a la Argentina e incorporarse a la vida universitaria ${ }^{1}$. Juan Carlos ya tenía un recorrido a sus espaldas (Fradkin, Gelman \& Santilli, 2018); basta recordar su intervención en el Cuaderno de Pasado y Presente (Garavaglia, 1973), su original contribución a un libro capital en el desarrollo de la historia agraria latinoamericana compilado por E. Florescano (Garavaglia, 1975) ${ }^{2}$ y la publicación de un análisis todavía no superado de la historia plurisecular de la yerba mate y el Paraguay colonial, basado en su tesis en la EHESS (Garavaglia, 1983) ${ }^{3}$. Sin embargo, algunas de las intuiciones decisivas que habrían de transformar la historia agraria rioplatense estaban prefiguradas en su precoz y original tesis de licenciatura, demostradas, por ejemplo, en el párrafo que transcribimos:

1. Juan Carlos nació en Pasto (Colombia) en 1944. Desde muy joven combinó sus estudios y actividades como historiador con la militancia política y lo hizo en las tendencias revolucionarias del peronismo hasta que partió al exilio; se graduó en la École des hautes études en sciences sociales (EHESS) en 1979. Cuando regresó a la Argentina se incorporó como profesor a la Universidad Nacional del Centro de la Provincia de Buenos Aires, donde contribuyó a la organización de su Instituto de Estudios Histórico-Sociales y a la aparición de su Anuario. Jorge nació en 1956 en Buenos Aires y también tuvo activa militancia en una organización trotskista y fue prisionero político en 1975 partiendo al exilio desde la cárcel. Obtuvo su doctorado en 1983 también en la EHESS. A su regreso a la Argentina se incorporó a la Facultad de Filosofía y Letras de la Universidad de Buenos Aires y a su Instituto «Dr. Emilio Ravignani».

2. En ese señero libro hubo solo dos estudios dedicados a las estancias rioplatenses: el de Juan Carlos, sobre las estancias del pueblo misionero de Yapeyú, y el de Tulio HaLPERín (1975b), que era parte de los análisis que venía realizando sobre la expansión ganadera bonaerense (HALPERín, 1969), la expansión de la frontera (HALPERíN, 1975a), estudios en los cuales Juan Carlos y Jorge se apoyaron para producir sus renovadas contribuciones de la historia agraria.

3. Una narración acerca de cómo Juan Carlos llegó a la historia agraria de Buenos Aires en FRADKIN y GELMAN (2017). 
La palabra "estancia» trae a todo argentino un cúmulo de imágenes de grandeza y señorío rural, que en esta época no corresponde muy ajustadamente con la realidad socioeconómica rioplatense. En este momento ser estanciero, es casi sinónimo de hombre de campo, y éste se encontraba bastante alejado de la riqueza que disfrutaban los grupos mercantiles que, a no dudar, eran los que poseían las llaves de la economía (Garavaglia, 1970: 85) ${ }^{4}$.

Cuarenta y cinco años después confirmaba esa dirección emprendida, reafirmando su convicción de que la vida material marca profundamente el accionar humano, su cultura, su historia, que no es otra que social (Garavaglia, 2015b: 144-145).

Juan Carlos entonces ya aquilataba una experiencia en el manejo de fuentes y en la aplicación de metodologías que había incorporado en su experiencia en el exilio francés y mexicano, y venía a la Argentina con la intención de utilizarlas. De modo que su reaparición en el Archivo General de la Nación (AGN, en adelante) para revisar fuentes que ya habían sido vistas infinidad de veces por numerosos investigadores y para rastrear otras completamente olvidadas o directamente inadvertidas, pasó a ser su hábito y costumbre más perdurable.

En cambio, Jorge Gelman (en adelante, JG) volvía con su flamante doctorado en la EHESS, conociendo y admirando los trabajos de Juan Carlos Garavaglia (en adelante, JCG), pero con inquietudes tan propias como convergentes. Si en su tesis había indagado la formación de la primera elite del Buenos Aires colonial, ahora estaba centrado en la investigación de un gran comerciante tardocolonial, Domingo Belgrano Peri, que daría como resultado su libro De mercachifle a gran comerciante: Los caminos del ascenso en el Rio de la Plata colonial (Gelman, 1996), y fue a través de esa investigación que un amplio universo de fuentes particularmente ricas para reconstruir la historia agraria atrapó su atención. Jorge siempre contaba cómo se acercó a Juan Carlos en una reunión académica, con respeto y cierto temor, reservas que desaparecieron inmediatamente. De ahí en más se formalizó una amistad que duraría el resto de sus vidas.

4. En esa misma tesis discutía la mirada que Ricardo Levene (1928) había propuesto sobre la gran expansión de la ganadería vacuna regional basada en el dato de sus exportaciones del año 1783. Como mostraba Juan Carlos, poniendo los datos cuantitativos de esos cinco años uno atrás del otro, ese año fue excepcional porque siguió a dos en los cuales el comercio se había prácticamente interrumpido. Y a su vez, luego de la gran exportación de cueros de ese año de reapertura comercial, bajaba al año siguiente a la mitad (GARAVAGLIA, 1970: 101). Una aproximación a la formación de Juan Carlos en FRADKIN (2017). 
Garavaglia se dedicó a trabajar con los diezmos de varias de las regiones del Virreinato, pero le prestó principal atención a los de Buenos Aires, para descubrir la importancia de la agricultura entre las actividades de su campaña en el siglo XVIII, trabajo que fue publicado en inglés en la The Hispanic American Historical Review (HAHR) (Garavaglia, 1985). Se trataba de una perspectiva original e inédita para el conocimiento hasta entonces aceptado, al punto que este artículo provocó muy diversas y opuestas reacciones: sorpresa, interés y desconfianza... Pero algo era claro: nadie -hasta entonceshabía intentado una exploración tan sistemática de la composición de la producción agraria tardocolonial. Por su parte, Gelman se embarcaba en la indagación también sistemática de unas fuentes apenas conocidas: la contabilidad de la estancia Las Vacas en Colonia, en el actual Uruguay, a las que había llegado siguiendo las pistas de Domingo Belgrano. Esas fuentes incluían riquísima información sobre los salarios, la nómina de trabajadores y sus tiempos de trabajo, ingresos por la venta de la producción de la estancia, el movimiento de la pulpería que les vendía productos a los jornaleros, etc. El resultado fue comprobar que, lejos de mantener una relación de completo dominio sobre los peones, la estancia afrontaba la volatilidad del empleo, dada no solo por la estacionalidad de las tareas ganaderas, sino también por las oportunidades laborales que ofrecía la agricultura y las actividades independientes de los trabajadores como productores autónomos 5 .

Las evidencias que habían develado, apelando a métodos y fuentes diferentes, eran tan contundentes como convergentes, y rompían con una tradición cultural e historiográfica muy larga y arraigada sobre el mundo rural rioplatense; comenzaba así a emerger un multifacético universo campesino. El uso del concepto campesino para analizar el mundo rural rioplatense levantó revuelo por los esquemas interpretativos que cuestionaba; era provocativo y se inspiraba en buena medida en los escritos de A. Chayanov y de su difusor entre nosotros, Eduardo Archetti (Chayanov, 1974), pero también en los estudios previos de Juan Carlos sobre Paraguay y México. La definición se apoyaba en que estos pequeños productores basaban su actividad en el uso de la fuerza de trabajo familiar y en la concurrencia al mercado para obtener, mediante la venta del sobrante de producción, fondos con que adquirir aquellos artículos de los que no podían autoabastecerse (Gelman, 1989a, 1989b). Aparecía, así, una nueva clave para comprender la inestabilidad laboral en las estancias alejada de la mitología forjada en torno al gaucho.

5. En parte, estas fuentes habían sido analizadas por Jonathan Brown en A Socio-Economic History of Argentina, 1776-1860 (1979: 41-46) y fueron retomadas por BROwN y Ricardo SALVATORE en «Trade y Proletarianization in Late Colonial Banda Oriental» (1987). Este artículo fue criticado por Jorge y suscitó una rica polémica interpretativa en el vol. 69, n. ${ }^{\circ} 4$ de 1989 de la misma revista (en español en FRADKIN, 1993: 83-160). 
Para entonces, también había conocido un estimulante artículo de Carlos Mayo (1984) y se estaba abriendo uno de los debates más fructíferos en la historia rioplatense: la polémica sobre el gaucho reunida en el n. ${ }^{\circ} 2$ del Anuario IEHS, y que tuvo como protagonistas a Carlos Mayo, Samuel Amaral, Jorge Gelman y Juan Carlos Garavaglia (Mayo et al., 1987). En realidad, el debate estaba concentrado en discutir sobre la mano de obra rural en la campaña de Buenos Aires, donde las posiciones se podrían resumir en la estacionalidad de las tareas y la preponderancia de la oferta o la demanda de dicha campaña. La marcada estacionalidad de las tareas implicaba un desajuste entre la oferta y la demanda; el momento de mayor necesidad de mano de obra de la estancia, la cosecha, coincidía con la mayor propensión del trabajador a dedicarse a su propio cultivo. Mayo afirmaba que el trabajador regulaba la oferta por diversas razones, entre ellas el apego a la ley del menor esfuerzo, basado en las facilidades que ofrecía la vida en la campaña (acceso relativamente fácil a la tierra y al ganado o a otros animales salvajes comestibles, etc.). Amaral ponía el acento en la regulación desde las estancias, es decir, en la demanda. Por su parte, Gelman y Garavaglia sostenían la funcionalidad existente entre la estancia y los productores independientes, de manera que ajustaban el requerimiento y la oferta de mano de obra a las necesidades propias de cada sector, en un equilibrio que por el momento no generaba conflictos mayores, más allá de la continua queja de los estancieros acerca de la ociosidad y vagancia de los pobladores, queja que se acrecentaba en los momentos de mayor demanda de mano de obra y que resultaba en la carestía de la fuerza de trabajo. Es decir, buena parte de los pobladores de la campaña eran peones por tiempo limitado y, a su vez, pequeños productores (campesinos) en otros momentos, amalgamando esas dos actividades; por otro lado, los estancieros aprovechaban esa yuxtaposición de actividades en su beneficio, ya que les evitaba sostener salarios durante prolongados tiempos muertos del ciclo productivo. Pero el debate derivó en quiénes eran esos trabajadores part-time, quiénes eran los gauchos, supuestos trabajadores rurales, ariscos según las fuentes. De allí los provocadores títulos de las contribuciones de JCG ( ¿Existieron los gauchos?») y de JG ("iGauchos o campesinos?»).

Estas coincidencias los llevaron a una primera publicación conjunta (Garavaglia \& Gelman, 1989) ${ }^{6}$, en la cual JG trabajaba el tema de la mano de obra ya citado (Gelman, 1989a) y JCG el de la producción (Garavaglia, 1989). La disputa sobre el carácter de la mano de obra rural bonaerense fue saldada con el tiempo a favor de la visión de nuestros homenajeados ${ }^{7}$, quienes no dejaron de publicar textos que argumentaban en favor

6. Es notable que, a pesar de las grandes convergencias, nunca escribieron un texto de investigación juntos, siempre hicieron investigaciones por separado que luego plasmaron en publicaciones que los tenían como protagonistas. Una excepción son los estados de la cuestión, que escribieron varios en castellano y en inglés $(1998,1995)$ y un texto de interpretación, muy valioso por cierto (2003). 
de su posición, incluso en espacios destinados a la divulgación (Gelman, 1989c; Garavaglia \& Fradkin, 1992). Todavía en 1995 publicaba JG un texto sobre el tema que generará una polémica intensa con entidades tradicionalistas (Gelman, 1995) ${ }^{8}$.

Jorge pasó a situar las reveladoras contabilidades de la estancia de Las Vacas en su contexto y estudió la producción triguera de la región (Gelman, 1992a), su circulación mercantil (Gelman, 1992b, 1993a) y la composición y dinámica de la población (Gelman, 1993b), estudios que sirvieron de base a su primer gran libro de la historia agraria, Campesinos y estancieros (Gelman, 1998a), una de las mejores y más completas reconstrucciones de una estructura agraria regional. Casi simultáneamente aparecía Pastores y labradores, de Garavaglia (1999a), el primer estudio sistemático y completo de la estructura agraria de la campaña de Buenos Aires colonial. Eran dos libros distintos, pero hermanados por preocupaciones comunes, intercambios fluidos y fructíferos ${ }^{9}$, así como por los avances que estaban aportando los trabajos de otros autores atraídos por el entusiasmo que ambos promovían ${ }^{10}$.

Por ejemplo, el notable impulso que adquirieron los estudios de demografía histórica. A partir de los trabajos de José Luis Moreno, y refutando contundentemente una imagen consagrada por la tradición historiográfica, se había llegado a comprobar la presencia mayoritaria de familias en la campaña. Se trataba de una cuestión clave para poder introducir la noción de campesino en el análisis de la organización socioeconómica y para demostrar que no había sólo grandes estancias y gauchos errantes y dispersos. JCG se sumó con entusiasmo a esta vía de análisis estudiando San Isidro (Garavaglia, 1993b) y San Antonio de Areco (Garavaglia, 1993c), un espacio emblemático al que le dedicaría años después un estudio de muy largo plazo, completamente original para la historiografía rioplatense (Garavaglia, 2009).

7. Por supuesto, seguía habiendo posturas que insistían en la centralidad del latifundismo colonial, su capacidad para someter a los trabajadores rurales y sustento del supuesto predominio indisputado de la ganadería, es decir, los núcleos claves de la visión tradicional de la campaña, por ejemplo, en AzcuY $(1995,2002)$. A su vez, también era muy distinta la interpretación que ofreció Amaral quien al tiempo que defendía la primacía de la ganadería colonial, cuestionando el análisis que Garavaglia había hecho de los diezmos, desarrolló su intervención en la polémica sobre el gaucho subrayando el carácter capitalista de las estancias (AMARAL \& GHIO, 1990; AMARAL, 1998).

8. La polémica citada fue relatada por JG en numerosas ocasiones y quedó en letras de molde en uno de sus últimos textos (2017a).

9. Solo basta ver para entenderlo las nueve páginas de bibliografía contemporánea que incluye Campesinos... y las doce de Pastores... A su vez, la interinfluencia de ambos es notoria: JG cita nueve textos de JCG y éste siete de su par.

10. Al respecto, remitimos a los variados estados de la cuestión escritos por ambos, ya citados. 
La contundencia de las evidencias no clausuró las investigaciones, sino que, por el contrario, las multiplicó, así como también impulsó el análisis sistemático de nuevos corpus documentales, la utilización de nuevas metodologías, y la formulación de nuevos problemas se puso a la orden del día. En la búsqueda de explicaciones del desenvolvimiento de la sociedad rioplatense, JCG inició sus estudios sobre testamentarias de habitantes de la campaña (Garavaglia, 1993a, 1999b), y pudo establecer la mayor importancia que tenía el valor del ganado por sobre el de la tierra en la composición de los establecimientos rurales, que gran parte de los pequeños productores ganaderos no eran propietarios de la tierra y que en la mayoría de los establecimientos productivos de la campaña había herramientas para la agricultura-lo que confirmaba su importancia y difusión aun en las zonas más volcadas a la ganadería-, y pudo validar por medio de otras fuentes los estudios basados en la recaudación del diezmo y los padrones de población. Más tarde pudo corroborarse, además, que la preponderancia del capital en ganado por sobre el de la tierra se mantenía aun en 1839: según el estudio basado en la recaudación de la contribución directa que encaró JG con Daniel Santilli, más del 60\% del capital total sujeto al impuesto era ganado y sólo el $35 \%$ al suelo, teniendo en cuenta además las parcelas otorgadas en enfiteusis, desde hacía ya quince años (Gelman \& Santilli, 2002). A conclusiones análogas había llegado JCG a partir de las evidencias proporcionadas por los inventarios de las estancias hasta mediados del siglo XIX.

En contradicción con las visiones predominantes, que habían ofrecido una imagen muy simple, arcaica y estereotipada de la campaña hasta mitad del siglo XIX, Jorge y Juan Carlos presentaban algo muy distinto, y demostraban la importancia y la persistencia de la pequeña producción y su papel de abastecedora de mercados emergentes como el de consumo de Buenos Aires. En ese sentido, ambos verificaron el acceso a los mercados de los pequeños productores y la importancia que ellos adquirieron para el abastecimiento de la ciudad, tanto en cuanto a los productos agrícolas como a la carne (Garavaglia, 1991, 1994; Gelman, 1993a, 1992b).

La producción agrícola, entonces, no había sido un fenómeno marginal en las pampas y no solo habría crecido durante la segunda mitad del XIX con la inmigración europea masiva, como se había supuesto. La exitosa y rápida incorporación al mercado mundial de Buenos Aires durante esas décadas provocó lo que JG denomino la gran divergencia con sus pares del interior (Gelman, 2010a, 2011a), una divergencia que también demostró JCG analizando los presupuestos de las entonces catorce provincias (Garavaglia, 2005). Por esta vía, y por otras complementarias -como los análisis que ambos emprendieron de la composición social del personal que gobernaba los pueblos y partidos rurales (los jueces de paz y sus subordinados)-, la historia económica y agraria que impulsaron pasó a examinar de un nuevo modo completamente diferente la construcción 
del Estado. Los análisis de la composición de los agentes de justicia en la campaña, antes y después de las reformas de 1821, permitió poner en valor una imagen más compleja de la sociedad rural: el incipiente Estado debía servirse de personajes con arraigo local y no solo ni principalmente en los grandes propietarios-; personajes que operaban muchas veces como portavoces de sus vecinos antes que como simples delegados del poder central, lo que demuestra lo dificultoso de la construcción del aparato estatal, una composición social que influyó en sus modos de administrar justicia a nivel local y sobre quienes desplegaban su accionar (Garavaglia, $1997^{11}$; Gelman, 2000).

La reconstrucción del orden tras la revolución fue para ambos un proceso lento y dificultoso, que se apoyará en la conformación de liderazgos personales, por un lado, y en la utilización del ejército como elemento represor y disuasivo de cualquier acto que no reconozca la supremacía del establishment, sea el rosista o el liberal. Ambos coincidieron en que ese nuevo orden en la campaña, del que la administración de justicia fue una piedra angular, llevó mucho más tiempo del que se suponía, aunque mantuviera muchos rasgos de continuidad con el colonial. El Estado es la sociedad, dice JG para reafirmar esa idea de continuidad; y si los cambios en la sociedad fueron lentos, la construcción del Estado también debía serlo (Gelman, 2000: 18).

El análisis de JG derivó en el estudio de la mano de obra en tiempos del gobernador Rosas, y más precisamente en sus estancias, es decir, el espacio arquetípico en que se sustentaba la imagen tradicional de la campaña bonaerense. En varios trabajos demostró las enormes dificultades que tuvieron los estancieros, incluido el propio Rosas, para conseguir y conservar a los trabajadores en sus establecimientos, tal como acontecía en la última etapa colonial. Pero bajo el rosismo las necesidades de mano de obra eran mucho más perentorias mientas que no habían cesado las condiciones que desde la oferta limitaban su flujo; es más, se profundizaron (Gelman, 1998b, 1999). De todos modos, las condiciones que permitieron el surgimiento de estos pequeños productores no habían desaparecido; persistieron por lo menos hasta la caída de Rosas, limitaron la adopción de nuevos métodos coactivos y debieron combinarse con una novedad que trajo la revolución al convertir a esos pobladores plebeyos en legitimadores y partícipes del sistema político institucional, lo que amplió sus posibilidades de negociación ante estancieros, jueces de paz y comandantes militares.

Se fueron delineando, así, dos campos de estudio específicos, ambos apoyados en las firmes evidencias aportadas por la historia agraria. Uno fue la conformación del Estado

11. Los trabajos de JCG fueron publicados también en su libro Poder, conflicto y relaciones sociales (GARAVAGLiA, 1999c). 
y el otro la evolución de la economía rural, pero con numerosos vasos comunicantes. Del primero se ocupó fundamentalmente JCG, y en el segundo se concentró JG. Por ejemplo, el estudio de la recaudación de la contribución directa, además de demostrar la riqueza de Buenos Aires y su distribución, sirvió para informar la construcción del aparato recaudador del Estado, sus dificultades, sus límites y sus éxitos (Gelman \& Santilli, 2006b).

Es que ambos coincidían en estudiar la marcha de la sociedad considerando los actores más diversos y los más humildes. En una economía que pronto iba a mostrar signos de un crecimiento fabuloso, a partir de su apertura a los mercados internacionales, una de las preguntas que se hacían era cómo se acomodaron los pobladores que se afincaban en el litoral, huyendo de escaseces y expulsiones en el interior, y cómo se acomodaban a los cambios políticos y sociales. En ese sentido JCG aseguraba que a él le

preocupa bien poco que las familias campesinas acumulen o no, no es mi objetivo en mis trabajos sobre el mundo campesino rioplatense. A mi me preocupa ahora verlos como actores sociales en el marco de las relaciones de poder locales (Fradkin et al., 2010: 40).

El punto era crucial, puesto que venía a poner en cuestión las explicaciones aceptadas de la gran expansión agraria pampeana basadas solo en las oportunidades y ventajas comparativas y que hacían foco solo en los grandes propietarios como sus protagonistas.

Para Gelman, los cambios producidos con la expansión de la economía porteña y su atlantización iban a generar pérdidas de derechos por parte de los sectores populares rurales a manos de los poderosos y un incremento de las desigualdades, tanto regionales como sociales.

Entonces, con un grupo de colegas nos propusimos estudiar estas desigualdades, abriendo asi un campo de estudios casi inexplorado que se reveló pronto como muy útil para entender los procesos históricos de la época (Gelman, 2017a: 54).

De esta manera, la comprensión y explicación acabada de las dinámicas históricas de la economía de Buenos Aires requerían de un examen simultáneo de sus diferencias y relaciones con las imperantes en otras economías regionales, y ello impuso la necesidad de desplegar investigaciones colectivas. De modo análogo, la comprensión acabada de la formación del Estado de Buenos Aires, primero, y del Estado nacional, después, también llevó a Juan Carlos a estudiar sistemáticamente las fiscalidades y presupuestos de otras formaciones estatales (Garavaglia, 2015a) y a impulsar una investigación colectiva de distintos procesos latinoamericanos de construcción estatal (Garavaglia \& Contente, 2011). 
En consecuencia, JG dedicó una gran cuota de su trabajo al estudio de la economía y de la desigualdad a lo largo del largo siglo xIx. El redescubrimiento y examen de la contribución directa de 1839 (Gelman \& Santilli, 2006a) fue la rendija que permitió observar con mayor precisión la sociedad y la economía de Buenos Aires y comenzar a comprender la primera mitad del siglo XIX como algo más que una suerte de prehistoria del modelo agroexportador, cuya partida de nacimiento solía datarse mucho después. Eduardo Míguez reconocía ese escaso interés de los historiadores de la segunda mitad por la etapa que estudiaron Garavaglia y Gelman, del poco lugar que hemos dado a la sociedad que sucumbe con Rosas, dijo textualmente en el análisis del libro de Juan Carlos sobre Areco (Fradkin et al., 2010:21) ${ }^{12}$.

Los trabajos sobre la contribución directa permitieron estudiar la distribución personal del capital en el conjunto de la campaña y el resultado fue observar una sociedad en 1839 muy desigual, pero no más que otras formaciones contemporáneas americanas. Sin embargo, lo más notable era que el $42 \%$ de las familias rurales accedía a posesiones; es decir, la desigualdad alta se conformaba con unos muy ricos propietarios, por un lado, y una infinidad de pequeños productores con y sin tierras propias, por el otro: reaparecían los campesinos. Estudios posteriores demostraron que no sólo pervivían, sino que lo siguieron haciendo por lo menos hasta 1867, aunque la desigualdad siguió creciendo y esa espiral se aceleró a partir de 1855 (Gelman, 2011b). Incluso más: trabajos posteriores permitieron establecer que la desigualdad en la distribución de la tierra era mayor en 1789 (Gelman \& Santilli, 2018a) que en 1839, cuando la expansión de la ganadería exportadora estaba plenamente consolidada. A partir de ese año se pudo constatar una espiral ascendente de la desigualdad que se aceleró en 1855, llegando a alcanzar en 1867 un nivel similar al de 1789. De modo que se puede observar una curva en forma de $U$ en la trayectoria de la evolución de la distribución de la tierra.

La reflexión de Jorge al respecto fue que probablemente la desigualdad luego de 1789 continuó creciendo hasta la revolución, para luego reducirse como producto de las guerras desatadas en la década de 1810 llegando a un piso desde el cual creció a partir de la expansión ganadera de la década de 1820; de este modo hacia 1839, si bien creció la desigualdad, se mantuvieron las condiciones que permitieron la supervivencia y reproducción de los campesinos a la par que se expandían las grandes estancias, aunque ya no tan interdependientes como había sucedido en la colonia. Si bien JG no tuvo tiempo de analizar la continuidad de este proceso hasta $1914^{13}$, vislumbraba, junto a Garavaglia, que

12. Para un análisis reciente de los desarrollos de la historia agraria, véase Eduardo MígueZ (2017).

13. Uno de los objetivos que se proponía JG cuando lo sorprendió la muerte era completar un panorama general hasta 1914, ya que contamos con las fuentes necesarias para cubrir la totalidad de la 
la segunda mitad del largo siglo, que convirtió a la Argentina en el granero del mundo, concluyó con la extensión de las relaciones capitalistas a toda la economía. Pero la explicación al respecto se había hecho sustancialmente más compleja y abría nuevos interrogantes, y aún espera respuesta la provocativa pregunta que ambos plantearon:

\begin{abstract}
De todos modos, la existencia en la región pampeana de una masa relevante de pequeños y medianos productores agropecuarios -decimos productores y no propietarios- es una realidad indudable y la pregunta es ¿qué pasó social y políticamente con esos actores que casi no tuvieron voz hasta los inicios del siglo xx? La respuesta a esa cuestión nos llevaría muy lejos y además, no estamos seguros -en el estado actual de nuestros conocimientos- que contemos con todos los elementos como para poderla contestar adecuadamente (Garavaglia \& Gelman, 2003: 120).
\end{abstract}

A pesar de que han transcurrido quince años desde ese trabajo, todavía estamos en los inicios de una investigación que pueda empezar a responderla.

Lo cierto es que, a pesar del crecimiento de la desigualdad, que en algunas ocasiones significó un deterioro de las condiciones de vida de los habitantes, la afluencia de población hacia la campaña continuó; es más, se incrementó en el último tercio del siglo con la llegada de la gran inmigración. ¿Por qué, si la desigualdad era tan grande, seguían llegando? El ensayo de respuestas fue una de las cuestiones que JG encaró con posterioridad, presumiendo que la desigualdad no excluye, por lo menos durante un tiempo, unas condiciones de vida aceptable; encaró así estudios sobre el nivel de vida.

Se comenzó con salarios, un clásico en este tipo de trabajos, que ya había estudiado Lyman Johnson para fines de la época colonial (1990). Luego de una etapa de variaciones el salario se estabilizó en un nivel bajo, golpeado por la inflación, pero a partir de 1840 comenzó un proceso de crecimiento muy importante, sobre todo en los sectores que reflejaban mejor el dinamismo de la economía, como la construcción (Gelman \& Santilli, 2014a, 2014b; Guzmán, 2018). Sin embargo, a través del estudio de las canastas de consumo se pudo establecer que, aun en los momentos de baja del salario, el nivel de vida de los asalariados permitía con creces la reproducción, y luego de 1840 fue más alto que el de muchas ciudades del mundo atlántico (Gelman \& Santilli, 2018b). Esta buenaventura se extendía a los trabajadores rurales dependientes y podemos suponer que, a los in-

campaña, en lo que respecta a la propiedad de la tierra, trabajo que el equipo que él conformó sigue realizando. Se trata de los libros de contribución directa publicados por el gobierno de la provincia de Buenos Aires (Ministerio de Hacienda de la Provincia de Buenos Aires, 1914) y algunos de cuyos avances ya han sido publicados (DJENDEREDJIAN \& SANTILLI, 2017; SANTILLI, 2016). 
dependientes también, que eran la mayoría. Para esto último se intentó valorizar el ingreso percibido por las actividades productivas de los campesinos, que en sus tiempos libres se conchababan $^{14}$. Se trabajó con el diezmo pagado por los productores en diversos espacios de la campaña porteña y de la Banda Oriental, pero sólo llegó a establecer los niveles de producción y de la desigualdad en ellos (Gelman \& Santilli, 2017). Como decía JG en su ya citado en innumerables oportunidades De la Historia agraria..., es una asignatura pendiente.

Estos trabajos sobre la desigualdad eran convergentes con los aportes que JCG había realizado sobre la economía de la campaña y confirmaron sus conclusiones sobre la composición del capital de los pobladores o el tamaño de los establecimientos y de su producción (Garavaglia, 1993a, 1999b). Pero fueron sus trabajos sobre precios de ganado y tierra (Garavaglia, 1995, 2004) los que abrieron un camino firme para estudiar la desigualdad medida desde el precio de la tierra y de los salarios (Gelman \& Santilli, 2015).

Del mismo modo, la constatación de la pervivencia de los campesinos impuso la necesidad de examinar las transformaciones y disputas de los derechos de propiedad (Gelman, 2005), y JG concluía que, a contramano de las convenciones aceptadas, la transición al capitalismo en la campaña había sido favorecida y no ralentizada por la existencia de esos pequeños productores y la persistencia de los antiguos derechos: No se puede considerar a esto como una traba al desarrollo capitalista de la región, sino como una de sus características principales (Garavaglia, 2005: 474) ${ }^{15}$. Se vislumbra en este trabajo aquello que Rosa Congost consignó como un método esencial de los historiadores preocupados por la propiedad, analizar más aquello que hacen los hombres con las normas antes que el estudio de ellas (Congost, 2006). Por eso, estudió los juicios de desalojo producidos en la campaña del período 1810-1863 para verificar lo dificultoso que resultaba para la élite imponer el derecho absoluto de propiedad y la domesticación de los sectores populares (Gelman, 2017b) ${ }^{16}$.

14. Ya en 2006 había realizado un cálculo del rendimiento de un establecimiento típicamente campesino, según la elaboración de Garavaglia en Pastores..., determinando que más de la mitad de los productores de ganado deberían conchabarse en 1839, ya que era más rentable que su propio establecimiento (GELMAN \& SANTILLI, 2006a: 86, 107).

15. Esta afirmación tiene que ver con una apreciación de la historiografía marxista que culpaba a Rosas de frenar al desarrollo capitalista (PUIGGRós, 1953), coincidiendo curiosamente -o no tantocon interpretaciones de seguidores de la Nueva Economía Institucional (IRIGOIN, 2000).

16. Un buen resumen de la concepción de las normas y de las costumbres relacionadas con los derechos de propiedad en el mundo occidental, en discusión con la Nueva Economía Institucional en Congost, Gelman y SANTos (2017), en especial la introducción y el epílogo. 
Es posible que la evaluación de ambos de la situación de los pequeños productores no fuera idéntica y que la mirada de Juan Carlos fuera más pesimista. Después de la caída de Rosas la imagen que nos devuelve es la de un campesino despojado rápidamente de sus derechos al uso de bienes que antes eran de libre disposición hasta la guerra del $\mathrm{Pa}-$ raguay (Garavaglia, 2001). Para Jorge todavía en 1867 los pequeños propietarios tenían un peso significativo en la recaudación de la contribución directa y podía decir que el incremento de la desigualdad tuvo más que ver con el agregado de nuevos pobladores que con el despojo de los antiguos ${ }^{17}$. Todavía en el censo de 1869 había 3,6 dependientes asalariados por cada productor (Sábato \& Romero, 1992), y ello indicaba que muchos productores no tenían dependientes permanentes. Por lo tanto, una buena parte de los campesinos no habían sido proletarizados.

Por último, Jorge Gelman se propuso estudiar la desigualdad en diversos espacios de la actual Argentina. Para ello, convocó a una serie de investigadores provenientes de los lugares que pretendía estudiar: Sara Mata de Salta, Cecilia Fandos de Jujuy, María Paula Parolo de Tucumán, Beatriz Bragoni y Patricia Olguín de Mendoza, Carina Frid de Rosario. Se agregaron investigadores que analizaron otros espacios: Julio Djenderedjian y Roberto Schmit para Entre Ríos, Juan Luis Martirén para las colonias santafesinas, Tomás Guzmán para la ciudad de Buenos Aires, y el mismo Gelman con Santilli para Córdoba. $\mathrm{El}$ resultado de este trabajo en conjunto fue el libro coordinado por Jorge, El mapa de la desigualdad en la Argentina del siglo XIX (Gelman, 2011b).

Una última conjunción merece ser destacada: la dimensión y la perspectiva latinoamericanista de sus estudios. En ningún momento de sus largas trayectorias pensaron a Buenos Aires, elVirreinato, a la Confederación o la República como separada del resto de América Latina. Ambos tuvieron presente la necesidad de explicar la historia argentina en el marco de la historia latinoamericana.Y en los años más recientes esa perspectiva se profundizó $^{18}$. La conformación del grupo State Building in Latin America marca la coronación de una concepción fundamental en JCG: indagar en varios países la fiscalidad ${ }^{19}$,

17. Hasta 1867 se comprobó que mientras la cantidad de propietarios crecía a razón del 2,8\% anual, la población lo hacía al 4,3\% (GELMAN \& SANTILLI, 2011); resulta así impensable que no aumentara la tasa de desigualdad.

18. En el caso de Garavaglia, se podría marcar un acercamiento temprano al tema de la construcción del Estado en su libro Construir el Estado... (GARAVAGLIA, 2007), y últimamente un artículo sobre los años de la Confederación Argentina (GARAVAGLIA, 2013) y su confrontación con Buenos Aires (GARAVAGLia, 2015a).

19. Un dossier sobre el tema puede consultarse en http://repositori.upf.edu/handle/10230/30. Garavaglia publicó un texto sobre la transición fiscal (GARAVAGLIA, 2010) y Gelman con un comentario de los trabajos sobre la mencionada transición (GELMAN, 2010b). 
la burocracia (Garavaglia \& Pro Ruiz, 2013) y las fuerzas de la guerra, entre otros aspectos (Garavaglia, Pro Ruiz \& Zimmermann, 2012). En sus últimos días JCG estaba embarcado en el estudio a fondo de una guerra ineludible para comprender la historia de las sociedades y estados: la de la Triple Alianza contra el Paraguay (Garavaglia \& Fradkin, 2017).

Por su parte, Jorge Gelman se introdujo en la historia económica latinoamericana, indagando sobre todo en la diferente repercusión de procesos como las reformas borbónicas o las revoluciones y su secuela de guerras. Comparó casos, como Perú y Argentina, por ejemplo (Gelman, 2009), hizo un recorrido por todo el espacio americano para mostrar las convergencias y divergencias (Gelman, 2011c) y analizó los resultados de las reformas borbónicas en el Río de la Plata (Gelman \& Moraes, 2015), entre otros estudios. Este texto fue su participación en el libro conjunto Iberoamérica y España antes de las independencias (Gelman, Llopis \& Marichal, 2014). Así como en el caso de Buenos Aires, JG atribuye las divergencias a la dotación de factores de cada región para producir materias primas baratas requeridas por la revolución industrial, con la posibilidad de aprovechar los avances del transporte en el Atlántico y poseer puertos sobre ese océano o estar relativamente cerca. Pero además demostraba -mencionado en el epílogo compartido por los tres coordinadores del libro citado- que las posibilidades de crecimiento no estaban siempre asociadas a la asunción de las nuevas instituciones liberales, como proclama la Nueva Economía Institucional, sino que lo lograban con las viejas reglas; es más, en espacios que habían asumido tempranamente las instituciones liberales no se produjeron crecimientos importantes.

Quisiéramos cerrar esta presentación recuperando algunas observaciones de Jorge anotadas en uno de sus últimos textos publicados, pues nos parecen extremadamente oportunas. Allí aportó una lúcida y generosa reflexión basada en su experiencia personal que testimonia con precisión las transformaciones producidas en este campo de estudios en las últimas cuatro décadas. En ellas Juan Carlos y Jorge tuvieron un papel decisivo y en torno suyo se agregaron toda una pléyade de investigadores de diversas generaciones. Jorge sintetizó las razones que explican estos cambios historiográficos: la ruptura con las convenciones y hábitos forjados por una larga tradición, la apertura del espectro documental y su explotación exhaustiva y sistemática, la adopción de una perspectiva latinoamericanista para enfocar la historia agraria argentina o la superación de las periodizaciones y regionalizaciones tradicionales, fueron parte ineludible. El tránsito empujado por Jorge de la historia agraria a una renovada historia de las desigualdades se convirtió en una vía fértil para renovar y recuperar el rol innovador de la historia económica y para darle a los historiadores una voz nueva y más consistente en los debates políticos de nuestro tiempo y colocar a la historia argentina dentro de los debates internacionales. Hacía tiempo que 
por esa senda iban sus preocupaciones cardinales, y su diagnóstico de los alcances y de los límites que afrontaba la historia agraria argentina en particular y la historia económica en general estaba asociado a las sendas que junto a Juan Carlos supieron transitar. Ante todo, la necesidad de trabajar con perspectivas temporales y espaciales más amplias, que permitan comparar estructuras y procesos de periodos que suelen estar disociados en la práctica historiográfica habitual, como, por ejemplo, el agro colonial y sus transformaciones a lo largo del siglo XIX. Luego, la necesidad de desarrollar una historia económica más sistemáticamente comparativa a fin de delimitar mejor los factores explicativos de los procesos apoyándose en una mayor reflexión teórica. Por consiguiente, la necesidad de volver de alguna manera a los grandes temas que preocupan a la sociedad y que supieron interesar a los historiadores económicos (como el crecimiento, el estancamiento, la desigualdad o la pobreza) y reabrir la discusión sobre sus causas, cronologías y características para poder intervenir más activa y decididamente en los debates sobre las crisis que regularmente azotan a la Argentina, y no solo a ella. Solo así, sugería Jorge, se logrará que la historia económica pueda volver a ocupar un lugar destacado en las explicaciones históricas (Gelman, 2017a). No era la defensa del interés corporativo lo que lo inspiraba: era, por el contrario, la fidelidad a las razones que lo habían llevado a hacerse historiador y que no eran sustancialmente distintas de las que habían empujado a Juan Carlos en esa dirección.

Ambos tenían muy en claro que se trataba de una tarea necesariamente colectiva. Por eso no sólo impulsaron libros colectivos que dieran cuenta de los avances de esta renovadora línea de investigación, sino que Jorge se dedicó con ahínco, entusiasmo e inaudita perseverancia a forjar en su querido Instituto Ravignani un gran proyecto de investigación colectiva en el que estuvieran involucrados y comprometidos la mayor parte de sus investigadores y becarios. A nosotros y a las nuevas camadas de historiadores nos toca hacernos cargo de ese legado ${ }^{20}$.

\section{AGRADECIMIENTOS}

Este trabajo comenzamos a escribirlo junto a Jorge Gelman con el objetivo de evaluar la contribución de Juan Carlos Garavaglia a la historia agraria rioplatense. Tras el fallecimiento de Jorge terminamos de redactarlo y fue presentado en el XVI Congreso de Historia Agraria-SEHA, celebrado en Santiago de Compostela en junio de 2018. Luego, de-

20. La bibliografía completa de Jorge Gelman puede consultarse en http://ravignani.institutos. filo.uba.ar/jorge-gelman-in-memoriam. La de Juan Carlos Garavaglia en https://www.unicen.edu.ar/ iehs/homenaje/juancarlosgaravaglia.html 
cidimos ampliar su contenido dando cuenta también de las contribuciones de Jorge. Por eso nuestro primer agradecimiento es hacia él. También agradecemos los comentarios de los ponentes y participantes de esa sesión, así como las valiosas sugerencias de los evaluadores anónimos de la revista Historia Agraria.

\section{REFERENCIAS}

Amaral, S. (1998). The Rise of Capitalism on the Pampas. Cambridge: Cambridge University Press.

Amaral, S. \& GHio, J. M. (1990). Diezmos y producción agraria: Buenos Aires, 17501800. Revista de Historia Económica, 8 (3), 619-647.

AzcuY, E. (1995). El latifundio y la gran propiedad colonial rioplatense. Buenos Aires: Fernando García Cambeiro.

Azcuy, E. (2002). La otra historia: Economía, Estado y sociedad en el Río de la Plata colonial. Buenos Aires: Imago Mundi.

Brown, J. C. (1979). A Socioeconomic History of Argentina, 1776-1860. Cambridge: Cambridge University Press.

Brown, J. C. \& Salvatore, R. (1987). Trade and Proletarianization in Late Colonial Banda Oriental: Evidence from the Estancia de las Vacas, 1791-1805. Hispanic American Historical Review, 67 (3), 431-459.

Chayanov, A. (1974). La organización de la unidad económica campesina. Buenos Aires: Nueva Visión.

Congost, R. (2006). Leyes liberales, desarrollo económico y discursos históricos: El test de los propietarios prácticos. En A. REGUERA (Coord.), Los rostros de la modernidad: Vias de transición al capitalismo: Europa y América Latina, siglos XIX-XX (pp. 25-44). Rosario: Prohistoria.

Congost, R., Gelman, J. \& Santos, R. (Eds.) (2017). Property Rights in Land: Issues in Social, Economic and Global History. London/New York: Routledge.

Djenderedjian, J. \& Santilli, D. (2017). En R. Congost, J. Gelman \& R. Santos (Eds.), Property Rights in Land: Issues in Social, Economic and Global History (pp. 7490). London/New York: Routledge.

Fradkin, R. (Comp.) (1993). La historia agraria del Río de la Plata colonia: Los establecimientos productivos. 2 tomos. Buenos Aires: Centro Editor de América Latina.

FRADKIN, R. (2017). Indicios y conjeturas: La formación de un historiador original. Prohistoria, xx (28), 257-275. http://www.scielo.org.ar/pdf/prohist/v28/v28a14.pdf

FRADKIN, R. \& GELMAN, J. (2017). Juan Carlos Garavaglia, hasta siempre. Anuario IEHS, 32 (1), 7-18. http://anuarioiehs.unicen.edu.ar/Files/2017\%201/01\%20Anuario \%20IEHS\%2032(1)\%20o.Fradkin\&Gelman.pdf 
Fradkin, R., Gelman, J., Barriera, D. G., Míguez, E. J., Hora, R., Palacio, J. M. \& GaraVAGLiA, J. C. (2010). Rupturas y continuidades en el agro bonaerense: Debates en torno a San Antonio de Areco, 1660-1180. Un pueblo de campaña, del Antiguo Régimen a la modernidad argentina de Juan Carlos Garavaglia. Anuario IEHS, (25), 1341. http://anuarioiehs.unicen.edu.ar/Files/2010/Rupturas $\% 20 \mathrm{y} \% 20$ continuidades\%20en\%20el\%20agro\%20bonaerense.pdf

Fradkin, R., Gelman, J. \& SANTiLli, D. (2018). Fuan Carlos Garavaglia y la historia agraria del área rioplatense: Un balance de 45 años. Santiago de Compostela: Sociedad de Estudios de Historia Agraria.

Garavaglia, J. C. (1970). El comercio virreinal 1779-1784. Tesis de licenciatura. Buenos Aires: Universidad de Buenos Aires.

Garavaglia, J. C. et al. (Comps.) (1973). Modos de producción en América Latina. Buenos Aires: Siglo XXI. (Cuadernos de Pasado y Presente, 40).

GaRAVAGLIA, J. C. (1975). Las actividades agropecuarias en el marco de la vida económica del pueblo de indios de Nuestra Señora de los Santos Reyes Magos de Yapeyú: 1768-1806. En E. FloRESCANO (Comp.), Haciendas, latifundios y plantaciones en América Latina (pp. 464-486). México, DF: Siglo XXI.

GaRAVAGLiA, J. C. (1983). Mercado interno y economía colonia:. Tres siglos de historia de la yerba mate. México, DF: Grijalbo.

Garavaglia, J. C. (1985). Economic Growth and Regional Differentiations: The River Plate Region at the End of the Eighteenth Century. The Hispanic American Historical Review, 65 (1), 51-89.

Garavaglia, J. C. (1989). Producción cerealera y producción ganadera en la campaña porteña, 1700-1820. En J. C. GARAVAGLIA \& J. GELMAN, El mundo rural rioplatense a fines de la época colonial: Estudios sobre producción y mano de obra. Buenos Aires: Biblos. (Cuadernos Simón Rodríguez, 17).

GaRAVAGLiA, J. C. (1991). El pan de cada día: El mercado del trigo en Buenos Aires, 17001820. Boletín del Instituto de Historia Argentina y Americana Dr. Emilio Ravignani, (4), 7-30. http://ravignanidigital.com.ar/_bol_ravig/n04/n04a01.pdf

GARAVAGLIA, J. C. (1993a). Las chacras y quintas de Buenos Aires: Ejido y campaña, 17501815. En R. MANDRINI \& A. REgUERA (Comps.), Huellas en la tierra: Indios, agricultores y hacendados en la pampa bonaerense (pp. 121-146). Tandil: Instituto de Estudios Histórico-Sociales.

Garavaglia, J. C. (1993b). Los labradores de san Isidro (siglos XVIII-XIX). Desarrollo económico, 32 (128), 513-542.

Garavaglia, J. C. (1993c). Migraciones, y estructuras familiares y vida campesina: Areco Arriba en 1815. En J. C. Garavaglia \& J. L. Moreno (Comps.), Población, sociedad, familia y migraciones en el espacio rioplatense, siglos XVIII y XIX (pp. 149-187). Buenos Aires: Cántaro. 
GaRAVAglia, J. C. (1994). De la carne al cuero: Los mercados para los productos pecuarios (Buenos Aires y su campaña, 1700-1825). Anuario IEHS, (9), 61-96. http://anuarioiehs.unicen.edu.ar/Files/1994/De\%20la\%20carne\%20al\%20cuero.\%20 Los\%20mercados\%20para\%20los\%20productos\%20pecuarios\%20(Buenos\%20Aires\%20y\%20su\%20campa\%C3\%B1a,\%201700-1825).pdf

GaRAVAGLia, J. C. (1995). Precios de los productos rurales y precios de la tierra en la campaña de Buenos Aires: 1750-1826. Boletín del Instituto de Historia Argentina y Americana «Dr. Emilio Ravignani», (11), 65-112. http://ravignanidigital.com.ar/_bol_ravig/n11/n11a03.pdf

Garavaglia, J. C. (1997). Paz, orden y trabajo en la campaña: La justicia rural y los juzgados de paz en Buenos Aires, 1830-1852. Desarrollo económico, 37 (146), 241-262.

Garavaglia, J. C. (1999a). Pastores y labradores de Buenos Aires: Una historia agraria de la campaña bonaerense 1700-1830. Buenos Aires: Ediciones de la Flor.

Garavaglia, J. C. (1999b). Un siglo de estancias en la campaña de Buenos Aires: 1751 a 1853. The Hispanic American Historical Review, 79 (4), 703-734.

Garavaglia, J. C. (1999c). Poder, conflicto y relaciones sociales: El Río de la Plata, XVIIIXIX. Rosario: Homo Sapiens.

Garavaglia, J. C. (2001). De Caseros a la guerra del Paraguay: El disciplinamiento de la población campesina en el Buenos Aires postrosista (1852-1865). Illes i Imperis, (5), 53-80. https://www.raco.cat/index.php/IllesImperis/article/view/69411

GaRAVAGLIA, J. C. (2004). La economía rural en la campaña de Buenos Aires vista a través de sus precios: (1756-1852). En R. FradKIn \& J. C. GARAVAGLIA, En busca de un tiempo perdido: La economía de Buenos Aires en el país de la abundancia, 1750-1865 (pp. 107-158). Buenos Aires: Prometeo.

GaraVAglia, J. C. (2005). Guerra y finanzas un cuarto de siglo después. En T. HALPERíN DongHI, Guerra y finanzas en los orígenes del Estado argentino: 1791-1850 (pp. 9-14). Buenos Aires: Prometeo.

Garavaglia, J. C. (2007). Construir el Estado, inventar la nación: El Río de la Plata, siglos XVIII-XIX. Buenos Aires: Prometeo Libros.

Garavaglia, J. C. (2009). San Antonio de Areco, 1680-1880: Un pueblo de la campaña, del Antiguo Régimen a la modernidad argentina. Rosario: Prohistoria.

GARAVAGLIA, J. C. (2010). Algunos aspectos preliminares acerca de la "transición fiscal» en América Latina, 1800-1850. Illes $i$ Imperis, (13), 159-192.

GARAVAGLiA, J. C. (2013). La construcción nacional en la Argentina: Rentas, presupuestos y niveles de estatalidad (1856-1865). Prohistoria, (20) 3-43. https://www.redalyc.org/articulo.oa?id=380134161001

GaRAVAGLIA, J. C. (2015a). La disputa por la construcción nacional argentina: Buenos Aires, la Confederación y las provincias, 1850-1865. Buenos Aires: Prometeo Libros. 
Garavaglia, J. C. (2015b). Una juventud en los años sesenta. Buenos Aires: Prometeo Libros.

Garavaglia, J. C. \& Contente, C. (2011). Configuraciones estatales, regiones y sociedades locales: América Latina, siglos XIX-XX. Barcelona: Bellaterra/State Bulding in Latin America.

Garavaglia, J. C. \& Fradkin, R. (1992). Hombres y mujeres de la colonia. Buenos Aires: Sudamericana.

Garavaglia, J. C. \& Fradkin, R. (Comps.) (2016). A 150 años de la guerra de la Triple Alianza contra el Paraguay. Buenos Aires: Prometeo Libros.

GaRAVAGLiA, J. C. \& GELMAN, J. (1989). El mundo rural rioplatense a fines de la época colonial: Estudios sobre producción y mano de obra. Buenos Aires: Biblos.

Garavaglia, J. C. \& Gelman, J. (1995). Rural History of Río de la Plata, 1600-1850: Results of a Historiographical Renaissance. Latin American Research Review, 30 (3), 75105. https://www.jstor.org/stable/2503980

Garavaglia, J. C. \& Gelman, J. (1998). Mucha tierra y poca gente: Un nuevo balance historiográfico de la historia rural platense (1750-1850). Historia Agraria, (15), 2950. http://hdl.handle.net/10234/123804

GaraVaglia, J. C. \& Gelman, J. (2003). Capitalismo agrario en la frontera: Buenos Aires y la región pampeana en el siglo XIX. Historia Agraria, (29), 105-122. http://www.historiaagraria.com/FILE/articulos/HA29_garavaglia.pdf

Garavaglia, J. C. \& Pro Ruiz, J. (Eds.) (2013). Latin American Bureaucracy and the State Building Process (1780-1860). Cambridge: Cambridge Scholars Publishing.

Garavaglia, J. C., Pro Ruiz, J. \& Zimmermann, E. (Eds.) (2012). Las fuerzas de guerra en la construcción del Estado: América Latina, siglo XIX. Rosario: Prohistoria.

GELMAN, J. (1989a). Sobre esclavos, peones, gauchos y campesinos: El trabajo y los trabajadores en una estancia colonial rioplatense. En J. C. GARAVAGLIA \& J. GELMAN, El mundo rural rioplatense a fines de la época colonial: Estudios sobre producción y mano de obra (pp. 43-83). Buenos Aires: Biblos.

Gelman, J. (1989b). Nuevas imágenes de un mundo rural: El Río de la Plata antes de 1810. Ciencia Hoy, 1 (5), 56-61.

Gelman, J. (1992a). Producción campesina y estancias en el Río de la Plata colonial: La región de Colonia a fines del siglo XviII. Boletín del Instituto de Historia Argentina y Americana «Dr. Emilio Ravignani», (6), 41-66. http://ravignanidigital.com.ar/_bol_ ravig/n06/n06a02.pdf

GELMAN, J. (1992b). Mundo rural y mercados: Una estancia y las formas de circulación mercantil en la campaña rioplatense tardocolonial. Revista de Indias, 52 (195-196), 477-514. 
Gelman, J. (1993a). Los caminos del mercado: Campesinos, estancieros y pulperos en una región del Río de la Plata colonial. Latin American Research Revieww, 28 (2), 89118. https://www.jstor.org/stable/2503579

GELMAN, J. (1993b). Familia y relaciones de producción en la campaña rioplatense colonial: Algunas consideraciones desde la Banda Oriental. En J. C. GARAVAGLIA \& J. L. Moreno (Comps.), Población, sociedad, familia y migraciones en el espacio rioplatense, siglos XVIII y XIX (pp. 75-103). Buenos Aires: Cántaro.

GELMAN, J. (1993c). Una región y una chacra en la campaña rioplatense: Las condiciones de la producción triguera a fines de la época colonial. En R. O. FRADKIN (Comp.), La historia agraria del Río de la Plata colonial: Los establecimientos productivos (t. 2, pp. 7-39). 2 tomos. Buenos Aires: Centro Editor de América Latina.

Gelman, J. (1995). El gaucho que supimos construir: Determinismo y conflictos en la historia argentina. Entrepasados, (9), 27-37.

Gelman, J. (1996). De mercachifle a gran comerciante: Los caminos del ascenso en el Río de la Plata colonial. La Rábida: Universidad Internacional de Andalucía.

Gelman, J. (1998a). Campesinos y estancieros: Una región del Río de la Plata a fines de la época colonial. Buenos Aires: Los libros del Riel.

GELMAN, J. (1998b). Un gigante con pies de barro: Rosas y los pobladores de la campaña. En N. Goldman \& R. Salvatore (Comps.), Caudillismo rioplatense: Nuevas miradas a un viejo problema (pp. 223-240). Buenos Aires: Eudeba.

Gelman, J. (1999). Las condiciones del crecimiento estanciero en el Buenos Aires de la primera mitad del siglo XIX:Trabajo, salarios y conflicto en las estancias de Rosas. En J. Gelman, J. C. Garavaglia \& B. Zeberio (Comps.), Expansión capitalista y transformaciones regionales: Relaciones sociales y empresas agrarias en la Argentina del siglo XIX (pp. 75-120). Buenos Aires: La Colmena/Universidad del Centro de la Provincia de Buenos Aires.

Gelman, J. (2000). Crisis y reconstrucción del orden en la campaña de Buenos Aires: Estado y sociedad en la primer mitad del siglo XIX. Boletin del Instituto de Historia Argentina yAmericana «Dr. Emilio Ravignani», (21), 7-32. http://ravignanidigital.com.ar/ _bol_ravig/n21/n21a01.pdf

Gelman, J. (2005). Derechos de propiedad, crecimiento económico y desigualdad en la región pampeana, siglos XVIII y XIX. Historia Agraria, (37), 467-488. http://www.historiaagraria.com/FILE/articulos/jorgegelman37.pdf

GeLman, J. (2009). ¿Crisis postcolonial en las economías sudamericanas?: Los casos del Río de la Plata y Perú. En E. Llopis \& C. MARICHAL (Coords.), Latinoamérica y España, 1800-1850: Un crecimiento económico nada excepcional (pp. 25-64). Madrid: Marcial Pons Historia/Instituto Mora.

Gelman, J. (2010a). La Gran Divergencia: Las economías regionales en Argentina después de la Independencia. En S. BANDIERI (Comp.), La historia económica y los pro- 
cesos de independencia en la América hispana (pp. 105-129). Buenos Aires: Asociación Argentina de Historia Económica/Prometeo Libros.

Gelman, J. (2010b). Comentarios: Los avatares de la transición fiscal y el ciclo económico: Algunos comentarios. Illes $i$ Imperis, (13), 203-213. https://www.raco.cat/index.php/IllesImperis/article/view/261643

GELMAN, J. (2011a). Introduccion: Desequilibrios regionales, desigualdades sociales: Las economías argentinas en el siglo xIx. En J. Gelman (Coord.), El mapa de la desigualdad en la Argentina del siglo XIX (pp. 11-46). Rosario: Prohistoria.

Gelman, J. (Comp.) (2011b). El mapa de la desigualdad en la Argentina del siglo XIX. Rosario: Prohistoria.

Gelman, J. (2011c). Senderos que se bifurcan: Las economías de América Latina luego de las Independencias. En L. BÉrTola \& P. GerChUnoff (Comps.), Institucionalidad y desarrollo económico en América Latina (pp. 19-46). Santiago de Chile: Comisión Económica para America Latina y el Caribe/Naciones Unidas. http://www.eclac.cl/publicaciones/xml/0/44960/Institucionalidad_y_desarrollo_1.pdf

Gelman, J. (2017a). De la historia agraria a la historia de las desigualdades. Anuario IEHS, 32 (2), 47-58. http://anuarioiehs.unicen.edu.ar/Files/2017\%202/03\%20Anuario\%20IEHS\%2032(2)\%20a.Gelman.pdf

Gelman, J. (2017b). La construccion del Estado en Buenos Aires y los derechos de propiedad: Una aproximación cuantitativa desde los juicios de desalojo, 1810-1863. Desarrollo Económico, 57 (221), 33-61. https://www.jstor.org/stable/44736467

Gelman, J. \& Moraes, M. I. (2015). Las reformas borbónicas y las economías rioplatenses: Cambio y continuidad. En J. Gelman, E. Llopis \& C. MARICHAL (Coords.), Iberoamérica y España antes de las independencias, 1700-1820: Crecimiento, reformas $y$ crisis (pp. 31-74). México, DF: Instituto Mora/El Colegio de México.

Gelman, J. \& SANTILli, D. (2002). Una medición de la economía rural de Buenos Aires en la época de Rosas: Expansión ganadera y diferencias regionales. Revista de Historia Económica, 20 (1), 81-106.

Gelman, J. \& Santilli, D. (2006a). De Rivadavia a Rosas: Desigualdad y crecimiento económico. Buenos Aires: Siglo XXI.

Gelman, J. \& SANTiLli, D. (2006b). Entre la eficiencia y la equidad: Los desafíos de la reforma fiscal en Buenos Aires, primera mitad del siglo xIx. Revista de Historia Económica, 24 (3), 491-520.

Gelman, J. \& SANTilli, D. (2011). ¿Cómo explicar la creciente desigualdad?: La propiedad de la tierra en Buenos Aires entre 1839 y 1867. En J. Gelman (comp.), El mapa de la desigualdad en la Argentina del siglo XIX (pp. 171-218). Buenos Aires: Prohistoria.

Gelman, J. \& SANTILli, D. (2014a). Los salarios y la desigualdad en Buenos Aires, 18101870. América Latina en la Historia Económica, 21 (3), 83-115. 
Gelman, J. \& Santilli, D. (2014b). Mar de fondo: Salarios, precios y los cambios en las condiciones de vida de los pobladores de Buenos Aires en una época convulsa, 18101870. En D. SANTILli, R. FRADKIN \& J. Gelman (Comps.), Rebeldes con causa: Conflicto y movilización popular en la Argentina del siglo XIX (pp. 121-148). Buenos Aires: Prometeo Libros.

Gelman, J. \& Santilli, D. (2015). Salarios y precios de los factores en Buenos Aires, 1770-1880: Una aproximación a la distribución funcional del ingreso en el largo plazo. Revista de Historia Económica, 33 (1), 153-186.

Gelman, J. \& SAntilli, D. (2017). La desigualdad en el Río de la Plata rural durante el período colonial: Una aproximación desde los diezmos. Ejes de Economía y Sociedad, (1), 69-85.

Gelman, J. \& SANTilli, D. (2018a). La distribución de la riqueza en el Buenos Aires rural entre finales de la colonia y la primera mitad del siglo XIX: ¿Una desigualdad moderada y en declive? América Latina en la Historia Económica, 25 (2), 7-41.

Gelman, J. \& SANTILLI, D. (2018b). Wages and Standards of Living in the $19^{\text {th }}$ Century from a Comparative Perspective: Consumption Basket, Bare Bone Basket and Welfare Ratio in Buenos Aires, 1825-1849. Investigaciones en Historia Económica, 14 (2), 94106.

Gelman, J., Llopis, E. \& MARICHAL, C. (Coords.) (2014). Iberoamérica y España antes de las independencias, 1700-1820: Crecimiento, reformas y crisis. México, DF: Instituto Mora/El Colegio de México.

GuZMÁN, T. (2018). Economía urbana y nivel de vida de los trabajadores: Los salarios de los peones albañiles. En XXVI fornadas de Historia Económica. Santa Rosa: Asociación Civil Argentina de Historia Económica.

HALPERÍN, T. (1969). La expansión ganadera en la campaña de Buenos Aires (1810-1852). En T. Di Tella \& T. HAlperín (Comps.), Los fragmentos del poder: De la oligarquía a la oliarquía argentina (pp. 21-73). Buenos Aires: Jorge Álvarez.

HALPERIN, T. (1975a). La expansión de la frontera de Buenos Aires (1810-1852). En M. GimÉNEZ ZAPIOLA (Comp.), El régimen oligárquico: Materiales para el estudio de la realidad argentina (hasta 1930) (pp. 58-71). Buenos Aires: Amorrortu.

HALPERín, T. (1975b). Una estancia en la campaña de Buenos Aires, Fontezuela, 17531809. En E. Florescano (Comp.), Haciendas, latifundios y plantaciones en América Latina (pp. 447-463). México, DF: Siglo XXI.

Irigorn, M. A. (2000). Inconvertible Paper Money, Inflation and Economic Performance in Early Nineteenth Century Argentina. Fournal of Latin American Studies, 32 (2), 333-359.

JoHnson, L. (1990). Salarios, precios y costo de vida en el Buenos Aires colonial tardío. Boletín del Instituto de Historia Argentina y Americana «Dr. Emilio Ravignani», (2), 133-157.http://ravignanidigital.com.ar/_bol_ravig/n02/n02a07.pdf 
LeVene, R. (1928). Investigaciones acerca de la historia económica del virreinato del Plata. La Plata: Universidad de La Plata.

MAYO, C. (1984). Estancia y peonaje en la región pampeana durante la segunda mitad del siglo XviII. Desarrollo Económico, 23 (92), 609-616.

Mayo, C., Amaral, S., Garavaglia, J. C. \& Gelman, J. (1987). Debate sobre la mano de obra rural. Anuario IEHS, (2), 21-70. http://anuarioiehs.unicen.edu.ar/1987.html

MígueZ, E. (2017). Del feudalismo al capitalismo agrario: ¿El fin de la historia... agraria? Boletin del Instituto de Historia Argentina y Americana "Dr. Emilio Ravignani», (46), 180-204.

Ministerio de Hacienda de la Provincia de Buenos Aires (1914). Primera guía de contribuyentes de los impuestos de contribución territorial, producción agropecuaria y caminos. 3 vols. La Plata: Gobernación.

Puiggrós, R. (1953). Rosas, el pequeño. Buenos Aires: Perennis.

Sábato, H. \& Romero, L. A. (1992). Los trabajadores de Buenos Aires: La experiencia del mercado, 1850-1880. Buenos Aires: Sudamericana.

SANTILLI, D. (2016). El precio de la «modernidad»: La evolución de la desigualdad en la propiedad de la tierra en la campaña de Buenos Aires, 1839-1914. Historia Agraria, (69), 73-103. http://www.historiaagraria.com/FILE/articulos/HA69_santilli.pdf 